ARTICLE

https://doi.org/10.1038/s41467-020-17752-x

\title{
Revealing the role of crystal orientation of protective layers for stable zinc anode
}

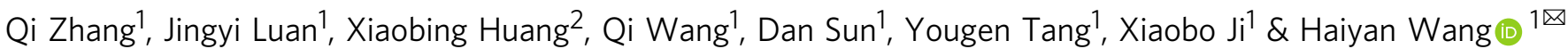

Rechargeable aqueous zinc-ion batteries are a promising candidate for next-generation energy storage devices. However, their practical application is limited by the severe safety issue caused by uncontrollable dendrite growth on zinc anodes. Here we develop faceted titanium dioxide with relatively low zinc affinity, which can restrict dendrite formation and homogenize zinc deposition when served as the protective layer on zinc anodes. The asprepared zinc anodes can be stripped and plated steadily for more than $460 \mathrm{~h}$ with low voltage hysteresis and flat voltage plateau in symmetric cells. This work reveals the key role of crystal orientation in zinc affinity and its internal mechanism is suitable for various crystal materials applied in the surface modification of other metal anodes such as lithium and sodium.

\footnotetext{
${ }^{1}$ Hunan Provincial Key Laboratory of Chemical Power Sources, College of Chemistry and Chemical Engineering, Central South University, Changsha 410083, P. R. China. ${ }^{2}$ College of Chemistry and Chemical Engineering, Hunan University of Arts and Science, Changde 415000, P. R. China.

凶email: wanghy419@csu.edu.cn
} 
A chieving higher energy density is the main development tendency for the next-generation battery system ${ }^{1}$. Metal anodes, such as lithium (Li), sodium $(\mathrm{Na})$, and zinc $(\mathrm{Zn})$, with high theoretical capacity and low electrochemical potential are considered as the most promising materials to meet this requirement ${ }^{2,3}$. However, the electrochemical performance of metal anodes is seriously affected by the dendrite formation during repeated charging and discharging. Metal dendrites are easily detached from anode mainbody and the newly exposed metal would react with electrolyte, leading to low Coulombic efficiency ${ }^{4,5}$. More seriously, separators may be punctured by the continuous dendrite growth, which directly causes the short circuit and poor cycle life of batteries ${ }^{6,7}$. Therefore, it is important to solve this issue for the industrialization of metal anodes.

Many approaches have been developed to achieve safer metal anodes, which mainly focus on two aspects: (1) improving metal deposition on current collectors. Nucleation can be facilitated by a three-dimensional structure with a uniform local electric field ${ }^{8,9}$. Some metal-affinity modification layers induced on current collectors are conducive to the adsorption of metal ions, which can guide the deposition and further alleviate dendrites ${ }^{10-12}$. (2) Optimizing the interface between metal and electrolyte. An artificial solid electrolyte interface (SEI) or an additional layer with inferior metal affinity can be applied as a protective layer to restrict dendrite growth ${ }^{13,14}$. Metal affinity is a key criterion to judge the applicable functions (guiding or restricting). However, taking titanium dioxide $\left(\mathrm{TiO}_{2}\right)$ for example, it can be used both for modification of current collectors and protection of metal anodes according to previous reports ${ }^{15-17}$. These results seem contradictory because good metal affinity is required when $\mathrm{TiO}_{2}$ is used as a decoration on current collectors to homogenize metal deposition while low metal affinity is necessary if it is served as a protective layer ${ }^{18,19}$. $\mathrm{TiO}_{2}$ can be simultaneously applied to two different metal modification strategies with opposite requirements, indicating that there is an ambiguous internal mechanism affecting its metal affinity. Considering that exposed facets of a crystal have a great influence on catalytic activity, metal affinity may be also controllable by adjusting surface exposure ${ }^{20,21}$.

In this work, the interactions between $\mathrm{Zn}$ and different facets of $\mathrm{TiO}_{2}$ are first investigated by density functional theory (DFT) calculation and it is concluded that the $\left(\begin{array}{lll}0 & 0 & 1\end{array}\right)$ and $\left(\begin{array}{lll}1 & 0 & 1\end{array}\right)$ facets of $\mathrm{TiO}_{2}$ show relatively low $\mathrm{Zn}$ affinity. Accordingly, $\mathrm{TiO}_{2}$ with highly exposed $\left(\begin{array}{lll}0 & 0 & 1\end{array}\right)$ facet is prepared and applied as the protective layer for $\mathrm{Zn}$ metal anodes. The $\left(\begin{array}{lll}0 & 0 & 1\end{array}\right)$ faceted $\mathrm{TiO}_{2}$ layer can effectively prevent $\mathrm{Zn}$ dendrites from growing vertically and stabilize the interface between anode and electrolyte. As a result, the modified $\mathrm{Zn}$ anode exhibits long-term cycle life during $\mathrm{Zn}$ stripping and plating.

\section{Results}

Theoretical analysis and characterization of faceted $\mathrm{TiO}_{2}$. The mechanism for the interaction between $\mathrm{Zn}$ and different facets of $\mathrm{TiO}_{2}$ is first investigated by DFT calculation. As shown in Fig. 1a-c and Supplementary Figs. 1 and 2, the models of $\mathrm{Zn}$ atoms attached to $\mathrm{TiO}_{2}$ surfaces and $\mathrm{Zn}$ surfaces were constructed. The $\mathrm{Zn}$ affinity of $\mathrm{TiO}_{2}$ surfaces can be judged by comparing the binding energy of $\mathrm{Zn}$ atom attached to the $\mathrm{TiO}_{2}$ surface and $\mathrm{Zn}$ surface. It can be considered that a $\mathrm{TiO}_{2}$ facet is with high $\mathrm{Zn}$ affinity if the binding energy of $\mathrm{Zn}$ atom attached to the corresponding $\mathrm{TiO}_{2}$ facet is higher than that on the $\mathrm{Zn}$ surface. As summarized in Fig. 1d, the binding energy between $\mathrm{Zn}$ atom and $\mathrm{TiO}_{2}\left(\begin{array}{lll}1 & 0 & 0\end{array}\right)$ facet is $-0.95 \mathrm{eV}$, higher than that between $\mathrm{Zn}$ atom and $\mathrm{Zn}$ surfaces $(-0.68$ and $-0.86 \mathrm{eV})$, indicating that $\mathrm{Zn}$ prefers to deposit on $\mathrm{TiO}_{2}\left(\begin{array}{lll}1 & 0 & 0\end{array}\right)$ facet in comparison to $\mathrm{Zn}$ surface. It is detrimental for a protective layer since this priority can lead to the growth of $\mathrm{Zn}$ dendrites upon the layer and deactivate the protective effect. In contrast, there is a weaker absorption of $\mathrm{Zn}$ on $\mathrm{TiO}_{2}\left(\begin{array}{lll}0 & 0 & 1\end{array}\right)$ and $\left(\begin{array}{lll}1 & 0 & 1\end{array}\right)$ facets with the binding energy of -0.63 and $-0.45 \mathrm{eV}$, respectively, which is mainly because the more exposure of the lower coordinated $\mathrm{Ti}$ on these facets exhibits more intense repulsion to $\mathrm{Zn}$ atom ${ }^{22}$. The interaction between $\mathrm{Zn}$ and different $\mathrm{TiO}_{2}$ facets is illustrated in Fig. 1e. According to the above analysis, the facet orientation plays a key role in $\mathrm{Zn}$ affinity and suitable materials for a protective layer can be achieved by controlling the exposure of specific facet.

As shown in Fig. 1f, the X-ray diffraction (XRD) patterns of the as-prepared faceted $\mathrm{TiO}_{2}\left(\mathrm{~F}-\mathrm{TiO}_{2}\right)$ and commercial $\mathrm{TiO}_{2}(\mathrm{C}$ $\mathrm{TiO}_{2}$ ) can be indexed to anatase $\mathrm{TiO}_{2}$. The average thickness along the growth direction of a crystal $(D)$ can be calculated by Scherrer equation ${ }^{23,24}$ :

$$
D=\frac{K \lambda}{\beta \cos \theta}
$$

where $K, \lambda, \beta$, and $\theta$ represent Scherrer constant, the wavelength of X-ray, full width at half maximum (FWHM) of diffraction peak and Bragg angle, respectively. For a specific crystal orientation, the larger FWHM in the XRD pattern indicates the smaller $D$ in this direction, in other words, the larger exposed area of the corresponding facet (Supplementary Fig. 3) 25 . Accordingly, the broader $\left(\begin{array}{lll}0 & 0 & 4\end{array}\right)$ peak in $\mathrm{F}_{-} \mathrm{TiO}_{2}$ demonstrates the larger exposure of $\left(\begin{array}{lll}0 & 0 & 1\end{array}\right)$ facet and the narrower $\left(\begin{array}{lll}2 & 0 & 0\end{array}\right)$ peak $\mathrm{F}-\mathrm{TiO}_{2}$ corresponds to the larger crystal size parallel to $\left(\begin{array}{lll}0 & 0 & 1\end{array}\right)$ facet, which is also the evidence of the relatively higher exposed area of $\left(\begin{array}{lll}0 & 0 & 1\end{array}\right)$ facet in comparison with $\mathrm{C}-\mathrm{TiO}_{2}{ }^{26}$. In Raman spectra (Supplementary Fig. 4), the characteristic peaks of anatase $\mathrm{TiO}_{2}$ appear at $392.3 \mathrm{~cm}^{-1}$ (symmetric bending vibration, $\mathrm{B}_{1 \mathrm{~g}}$ ), $513.7 \mathrm{~cm}^{-1}$ (antisymmetric bending vibration, $\mathrm{A}_{1 \mathrm{~g}}$ ), $636.5 \mathrm{~cm}^{-1}$ (symmetric stretching vibration, $\left.\mathrm{E}_{\mathrm{g}}\right)^{27}$. The 3 -coordinated titanium $(\mathrm{Ti})$ atoms on the $\left(\begin{array}{lll}0 & 0 & 1\end{array}\right)$ surface (Supplementary Fig. 5a) with lower coordination number than the 5-coordinated Ti atoms on $\left(\begin{array}{lll}1 & 0 & 0\end{array}\right)$ surface (Supplementary Fig. 5b) tend to show stronger bending vibration ${ }^{28}$. Therefore, the weaker $\mathrm{A}_{1 \mathrm{~g}}$ and $\mathrm{B}_{1 \mathrm{~g}}$ peaks in the Raman spectrum of $\mathrm{F}-\mathrm{TiO}_{2}$ suggest its higher exposure of $\left(\begin{array}{lll}0 & 0 & 1\end{array}\right)$ facet. Transmission electron microscopy (TEM) images (Supplementary Fig. 6) clearly show the nanosheet structure of $\mathrm{F}_{-}-\mathrm{TiO}_{2}$ with average width and thickness of 50 and $5 \mathrm{~nm}$, respectively. From the side view of $\mathrm{F}_{-}-\mathrm{TiO}_{2}$ nanosheet (Fig. 1g), lattice fringes with a lattice spacing of $0.235 \mathrm{~nm}$ are observed, which demonstrates that the $\left[\begin{array}{lll}0 & 0 & 1\end{array}\right]$ direction is perpendicular to the top surface. Figure $2 \mathrm{~h}$ is the top-view high-resolution transmission electron microscopy (HRTEM) image of $\mathrm{F}-\mathrm{TiO}_{2}$ nanosheet. There are orthogonal lattice fringes with equal lattice spacing $(0.19 \mathrm{~nm})$ inside the nanosheet (Fig. 1i), corresponding to [ $\left[\begin{array}{lll}1 & 0 & 0\end{array}\right]$ and $\left[\begin{array}{lll}0 & 1 & 0\end{array}\right]$ directions (both belong to $\left\langle\begin{array}{lll}1 & 0 & 0\end{array}>\right.$ family of directions). Therefore, the normal direction of top surface is $\left[\begin{array}{lll}0 & 0 & 1\end{array}\right]$ direction perpendicular to both $\left[\begin{array}{lll}1 & 0 & 0\end{array}\right]$ and $\left[\begin{array}{lll}0 & 1 & 0\end{array}\right]$ directions ${ }^{29}$. According to the observation of side-view and top-view HRTEM images, it is confirmed that $\left(\begin{array}{lll}0 & 0 & 1\end{array}\right)$ facet is the highly exposed top surface of F$\mathrm{TiO}_{2}$ nanosheet. Another set of orthogonal lattice fringes corresponding to $\left[\begin{array}{lll}1 & 0 & 1\end{array}\right]$ and $\left[\begin{array}{lll}0 & 1 & 0\end{array}\right]$ directions (Fig. $\left.1 \mathrm{j}\right)$ indicates the existence of $\left(\begin{array}{lll}1 & 0 & -1\end{array}\right)$ or $\left(\begin{array}{lll}-1 & 0 & 1\end{array}\right)$ facets (equivalent to $\left(\begin{array}{lll}1 & 0 & 1\end{array}\right)$ facet because of the tetragonal symmetry) at the edge of nanosheet $^{30}$. Besides, the side surface intersects the top $\left(\begin{array}{lll}0 & 0 & 1\end{array}\right)$ surface at an obtuse angle (Fig. $1 \mathrm{~g}$ and Supplementary Fig. 6c). It can be concluded that the side surface of $\mathrm{F}-\mathrm{TiO}_{2}$ nanosheet is ( 1 0 1) facet rather than the vertical $\left(\begin{array}{lll}1 & 0 & 0\end{array}\right)$ facet. The percentage of the exposed $\left(\begin{array}{lll}0 & 0 & 1\end{array}\right)$ and ( $\left.\begin{array}{lll}1 & 0 & 1\end{array}\right)$ facets can be calculated to be $83 \%$ and $17 \%$, respectively, by considering the nanosheet as a compressed square frustum. With regard to $\mathrm{C}-\mathrm{TiO}_{2}$ (Supplementary Fig. 7), it exhibits a nanoparticle morphology with an 


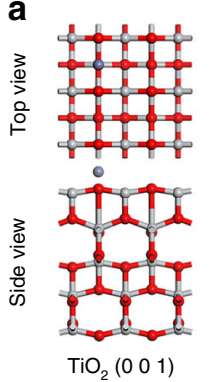

b
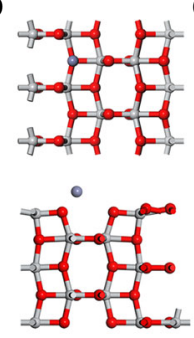

$\mathrm{TiO}_{2}\left(\begin{array}{lll}1 & 0 & 0\end{array}\right)$
C

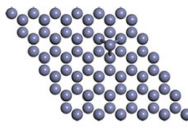

00080

000000

100

-

Zn ( $\left.\begin{array}{llll}0 & 0 & 1\end{array}\right)$

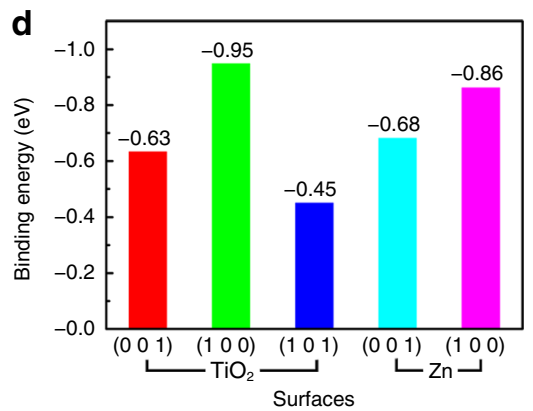

e

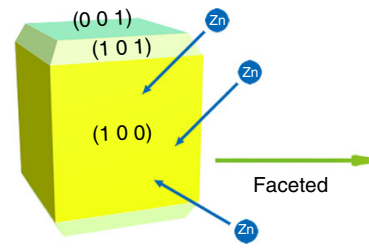

$\mathrm{TiO}_{2}$ bulk

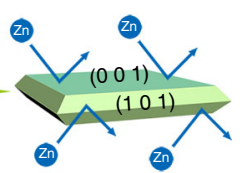

$\mathrm{TiO}_{2}$ sheet
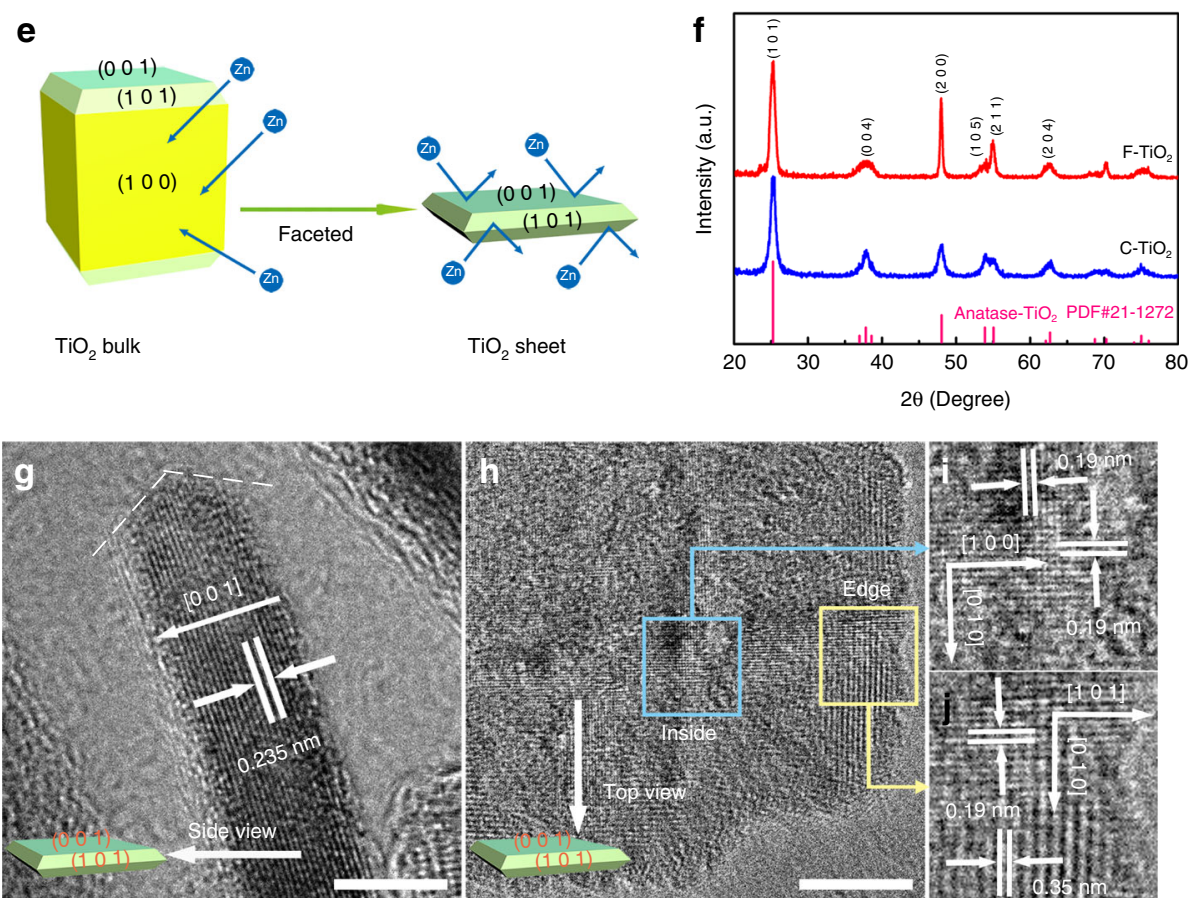

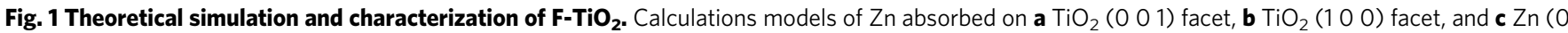
0 1) facet. $\mathbf{d}$ Calculated binding energies of $\mathrm{Zn}$ atom with different facets. e Schematic illustration of the interaction between $\mathrm{Zn}$ and anatase $\mathrm{TiO}_{2}$ with different exposed facets. $\mathbf{f}$ XRD patterns of $\mathrm{F}^{-\mathrm{TiO}_{2}}$ and $\mathrm{C}-\mathrm{TiO}_{2}$. $\mathbf{g}-\mathbf{j}$ HRTEM images of $\mathrm{F}-\mathrm{TiO}_{2}$. Scale bars: $5 \mathrm{~nm}$.

a

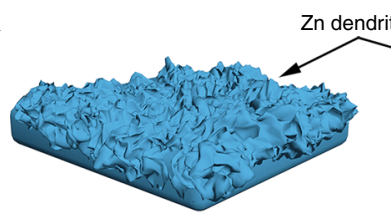

ZF

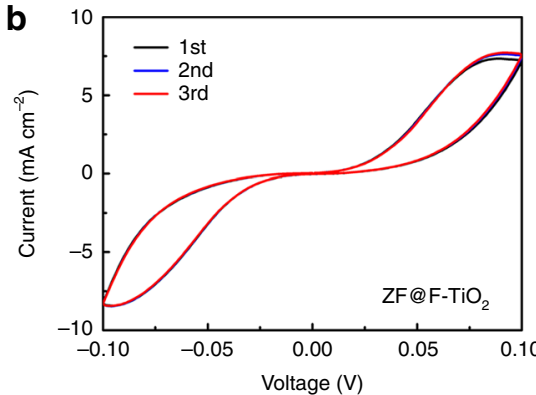

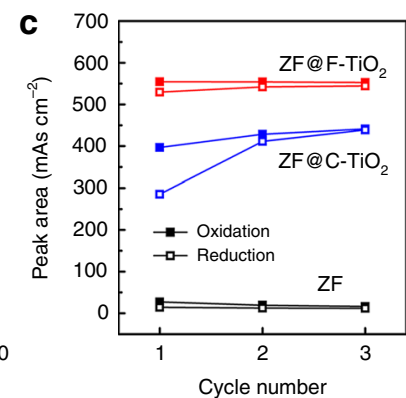

Coating layers
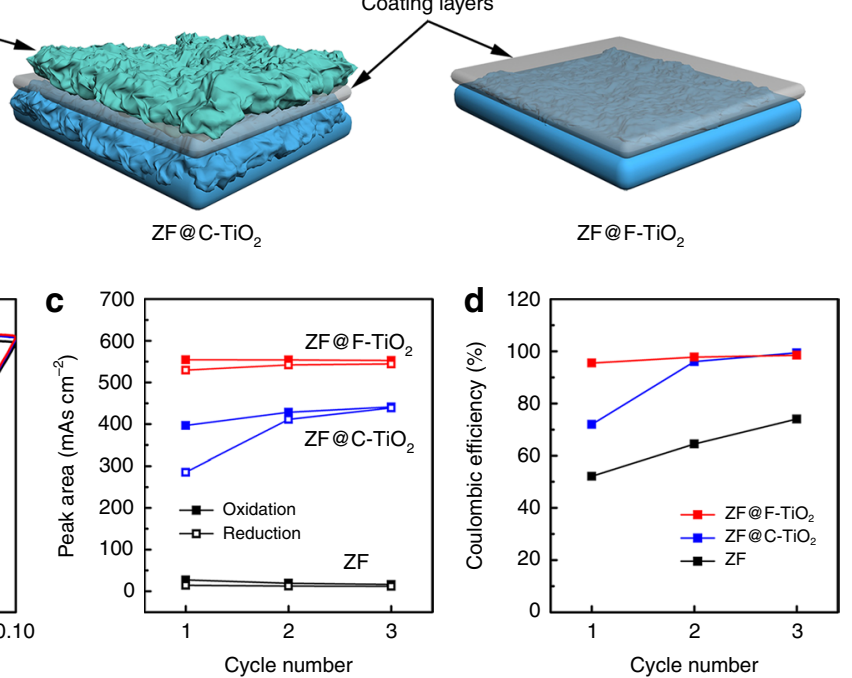

Fig. $2 \mathrm{Zn}$ deposition behavior of the prepared anodes. a Schematic illustration of the $\mathrm{Zn}$ plating process with different coating layers. $\mathbf{b} \mathrm{CV}$ curves of $\mathrm{Zn}-\mathrm{Zn}$ symmetric cells using $\mathrm{ZF} @ \mathrm{~F}-\mathrm{TiO}_{2}$ anode measured at $1 \mathrm{mV} \mathrm{s}{ }^{-1}$. Peak areas of $\mathrm{Zn}$ stripping/plating reactions (c) and corresponding Coulombic efficiency (d) of the prepared $\mathrm{Zn}$ anodes in $\mathrm{Zn}-\mathrm{Zn}$ symmetric cells. 
average diameter of $20 \mathrm{~nm}$ and the irregular lattice fringes indicate its random growth orientation, which leads to more exposure of $\mathrm{TiO}_{2}\left(\begin{array}{lll}1 & 0 & 0\end{array}\right)$ facets. The large area of extra $\mathrm{TiO}_{2}\left(\begin{array}{ll}1 & 0\end{array}\right.$ 0 ) facet is detrimental to prevent the growth of $\mathrm{Zn}$ dendrites. Accordingly, it is believed that $\mathrm{F}-\mathrm{TiO}_{2}$ nanosheets with exposed $\left(\begin{array}{lll}0 & 0 & 1\end{array}\right)$ and $\left(\begin{array}{lll}1 & 0 & 1\end{array}\right)$ facets can completely shield $\mathrm{Zn}$ and restrict the formation of dendrites.

Electrochemical performance of $\mathrm{F}_{-} \mathrm{TiO}_{2}$ as a protective layer. $\mathrm{TiO}_{2}$ protective layer was introduced on $\mathrm{Zn}$ anode by a simple blade coating method and the corresponding XRD pattern (Supplementary Fig. 8) demonstrates that the composite $\mathrm{Zn}$ anode is successfully synthesized. The $\mathrm{Zn}$ plating process on different $\mathrm{Zn}$ anodes is illustrated in Fig. 2a. Charges and ions tend to accumulate on the small tips at the surface of commercial $\mathrm{Zn}$ foil anodes when there is an impressed voltage. The resulting uneven interfacial electric field and ion concentration can induce preferential $\mathrm{Zn}$ growth and eventually lead to the formation of $\mathrm{Zn}$ dendrites during the repeated stripping and plating cycles ${ }^{31}$. When using $\mathrm{C}-\mathrm{TiO}_{2}$ as the intermediate layer, $\mathrm{Zn}$ tends to grow on the surface of $\mathrm{TiO}_{2}$ layer with a higher $\mathrm{Zn}$ affinity. For comparison, the $\mathrm{Zn}$ plating reaction can be well confined under the protective layer and the smooth $\mathrm{Zn}$ layer can be deposited on the $\mathrm{Zn}$ anode by faceting the $\mathrm{TiO}_{2}$ to specific orientations with low $\mathrm{Zn}$ affinity. The cyclic voltammetry $(\mathrm{CV})$ curves of $\mathrm{F}-\mathrm{TiO}_{2}$ coated $\mathrm{Zn}$ foil $\left(\mathrm{ZF} @ \mathrm{~F}-\mathrm{TiO}_{2}\right)$ in $\mathrm{Zn}-\mathrm{Zn}$ symmetric cells (Fig. 2b) can almost maintain the identical shapes in comparison with the changed peaks of $\mathrm{C}-\mathrm{TiO}_{2}$ coated $\mathrm{Zn}$ foil $\left(\mathrm{ZF} @ \mathrm{C}-\mathrm{TiO}_{2}\right)$ and $\mathrm{Zn}$ foil (ZF) (Supplementary Fig. 9), which indicates the superior reversibility of $\mathrm{Zn}$ stripping/plating in $\mathrm{ZF@F-TiO} 2$ anode. The peak areas of each redox reaction of $\mathrm{CV}$ curves can be obtained by integration operation (Fig. 2c). The larger peak area of ZF@F$\mathrm{TiO}_{2}$ anode reflects the enhanced interfacial activity for $\mathrm{Zn}$ deposition ${ }^{32} . \mathrm{Zn}^{2+}$ driven by the electric field and concentration gradient migrate toward the $\mathrm{Zn}$ anode and tend to be repulsed by the $\mathrm{F}_{-}-\mathrm{TiO}_{2}$ layer at the interface, leading to the $\mathrm{Zn}^{2+}$ accumulation near the anode surface. The increased $\mathrm{Zn}^{2+}$ concentration can not only activate more binding sites for $\mathrm{Zn}$ deposition but also accelerate the $\mathrm{Zn}^{2+}$ transfer rate on the surface to alleviate the uneven $\mathrm{Zn}^{2+}$ distribution, which is beneficial to the ordered interfacial $\mathrm{Zn}$ deposition ${ }^{33,34}$. Moreover, the highest Coulombic efficiency (reduction/oxidation) of $\mathrm{ZF@F-TiO} 2$ among all the prepared anodes (Fig. 2d) is also the evidence of its superior reversibility, which can be ascribed to the more uniform $\mathrm{Zn}$ deposition and less formation of "dead $\mathrm{Zn}$ ". $\mathrm{TiO}_{2}$ coated $\mathrm{Zn}$ foils exhibit better hydrophilicity than pure $\mathrm{Zn}$ foil (Supplementary Fig. 10), indicating that electrolyte can penetrate $\mathrm{TiO}_{2}$ layers to facilitate $\mathrm{Zn}^{2+}$ transport towards anode surface. The voltage profiles of the first ten cycles of zinc-stainless steel (Zn-SS) cells were recorded, which are shown in Supplementary Fig. 11. Pure $\mathrm{Zn}$ foil fails rapidly within $600 \mathrm{~min}$ due to the short circuit caused by the formation of dendrites. And the cycling stability of the cells is significantly improved when $\mathrm{Zn}$ foils are coated with the $\mathrm{TiO}_{2}$ interface layer. Specifically, ZF@F-TiO 2 exhibits longer cycling life than $\mathrm{ZF} @ \mathrm{C}-\mathrm{TiO}_{2}$, indicating its better $\mathrm{Zn}$ reversibility achieved by the specific exposed facets.

$\mathrm{Zn}$ anodes were extracted from $\mathrm{Zn}$-SS cells and their digital photographs are shown in Supplementary Fig. 12. Some unevenly distributed crystals are formed on the surface of ZF and ZF@C$\mathrm{TiO}_{2}$, while ZF@F-TiO 2 can maintain the original structure of F$\mathrm{TiO}_{2}$ layer. Scanning electron microscope (SEM) images of these cycled electrodes were also compared with the fresh anodes (Fig. 3). The morphologies of $\mathrm{ZF@F-TiO}$ and $\mathrm{ZF@C-TiO}$ are consistent before cycling. $\mathrm{TiO}_{2}$ coating layer with a smooth surface and uniform thickness $(20 \mu \mathrm{m})$ is in close contact with $\mathrm{Zn}$ foil. After cycling, there is no obvious change in $\mathrm{ZF} @ \mathrm{~F}-\mathrm{TiO}_{2}$ and its interface is still tightly combined. The well-defined distribution of $\mathrm{Ti}$ and $\mathrm{Zn}$ in the energy dispersive X-ray (EDX) mapping images (Fig. 3c, f) also demonstrates the good reversibility during stripping and plating cycles. As shown in Fig. 3 j, $\mathrm{k}, \mathrm{Zn}$ sheets ( $3 \mu \mathrm{m}$ in length) are observed on the surface of cycled ZF@C- $\mathrm{TiO}_{2}$, which is easily turned into $\mathrm{Zn}$ dendrites and causes the safety problem. $\mathrm{C}-\mathrm{TiO}_{2}$ layer seems ineffective due to a large amount of $\mathrm{Zn}$ transferred from $\mathrm{Zn}$ foil and the formation of void space at the interface. The process of $\mathrm{Zn}$ transfer to the surface can be seen in the EDX mapping image (Fig. 31). Supplementary Fig. 13 exhibits the more disordered surface with the wild growth of $\mathrm{Zn}$ dendrites on the cycled pure $\mathrm{Zn}$ foil, which is in agreement with the short-circuited Zn-SS cell within 10 cycles. From the different morphologies mentioned above, it is proved that the facet orientation plays an important role in adjusting $\mathrm{Zn}$ deposition behavior and $\mathrm{TiO}_{2}$ protective layer with highly exposed $\left(\begin{array}{lll}0 & 0 & 1\end{array}\right)$ facet with low $\mathrm{Zn}$ affinity can completely confine the $\mathrm{Zn}$ deposition in the restricted space. Besides, the $\mathrm{TiO}_{2}$ layer on the cycled anodes was removed by using methyl-2-pyrrolidinone (NMP) to dissolve polyvinylidene difluoride (PVDF) in the layers. As seen from the SEM images of the $\mathrm{Zn}$ surface after cycling (Supplementary Fig. 14), $\mathrm{Zn}$ deposition in $\mathrm{ZF@F-TiO} 2$ is flat and tends to accumulate parallel to the $\mathrm{Zn}$ surface, which also suggests the limited $\mathrm{Zn}$ growth by $\mathrm{F}-\mathrm{TiO}_{2}$ protective layer with decreased $\mathrm{Zn}$ affinity.

The positive effect of the $\mathrm{F}_{-} \mathrm{TiO}_{2}$ layer on $\mathrm{Zn}$ plating behavior was further investigated by testing the cycling stability of $\mathrm{Zn}$ anodes in $\mathrm{Zn} / \mathrm{Zn}$ symmetric cells. As shown in Fig. 4a, ZF@F$\mathrm{TiO}_{2}$ can be operated steadily for more than $460 \mathrm{~h}$ at $1 \mathrm{~mA} \mathrm{~cm}^{-2}$ for $1 \mathrm{mAh} \mathrm{cm}{ }^{-2}$, which is much superior to $\mathrm{ZF@C-TiO} 2(190 \mathrm{~h})$ and $\mathrm{ZF}(20 \mathrm{~h})$. When increasing the current density to $2 \mathrm{~mA} \mathrm{~cm}^{-2}$ and the specific capacity to $2 \mathrm{mAh} \mathrm{cm}^{-2}$ (Fig. $4 \mathrm{~b}$ ), $\mathrm{ZF@F-TiO}$ can still charge and discharge for $280 \mathrm{~h}$ in contrast to the quick failure of $\mathrm{ZF@C-TiO}$ and $\mathrm{ZF}$ with the shorter lifespan of 115 and $15 \mathrm{~h}$, respectively. Besides, $\mathrm{ZF} @ \mathrm{~F}-\mathrm{TiO}_{2}$ exhibits the most stable voltage plateau and the lowest voltage hysteresis, reflecting the enhanced $\mathrm{Zn}$ transfer kinetics ${ }^{35}$. The electrochemical performance of $\mathrm{ZF} @ \mathrm{~F}-\mathrm{TiO}_{2}$ is competitive in comparison with several $\mathrm{Zn}$ anodes using protective coating materials (Supplementary Table 1). The full cells were assembled with the as-prepared $\mathrm{Zn}$ anodes and commercial manganese dioxide $\left(\mathrm{MnO}_{2}\right)$ cathode. The full cell using $\mathrm{ZF} @ \mathrm{C}-\mathrm{TiO}_{2}$ anode exhibits the lowest polarization voltage and best cycling performance with the capacity retention ratio of $84.1 \%$ after 300 cycles (Supplementary Fig. 15). The enhanced full cell performance using the $\mathrm{F}-\mathrm{TiO}_{2}$ layer suggests its potential for practical application.

\section{Discussion}

High-performance $\mathrm{Zn}$ anode without external dendrite growth was fabricated by coating $\mathrm{TiO}_{2}$ with highly exposed $\left(\begin{array}{lll}0 & 0 & 1\end{array}\right)$ facet on commercial $\mathrm{Zn}$ foil. Benefiting from the specific crystal orientation of $\mathrm{TiO}_{2}$ with abomination to $\mathrm{Zn}$ absorption, $\mathrm{Zn}^{2+}$ transferred by the electric field was enriched on the anode surface. Thus, the increased interfacial $\mathrm{Zn}^{2+}$ concentration could induce uniform nucleation and the further $\mathrm{Zn}$ deposition was guided to grow laterally. The as-prepared $\mathrm{Zn}$ anode exhibited superior $\mathrm{Zn}$ stripping and plating performance with a long lifespan $(460 \mathrm{~h}$ at $1 \mathrm{~mA} \mathrm{~cm}^{-2}$ for $1 \mathrm{mAh} \mathrm{cm}^{-2}$ ). More importantly, the strategy to change the $\mathrm{Zn}$ affinity by adjusting the exposure of the facet provides a deep insight into the internal mechanism of metal affinity and can be extended to interfacial modification for other metal anodes. 


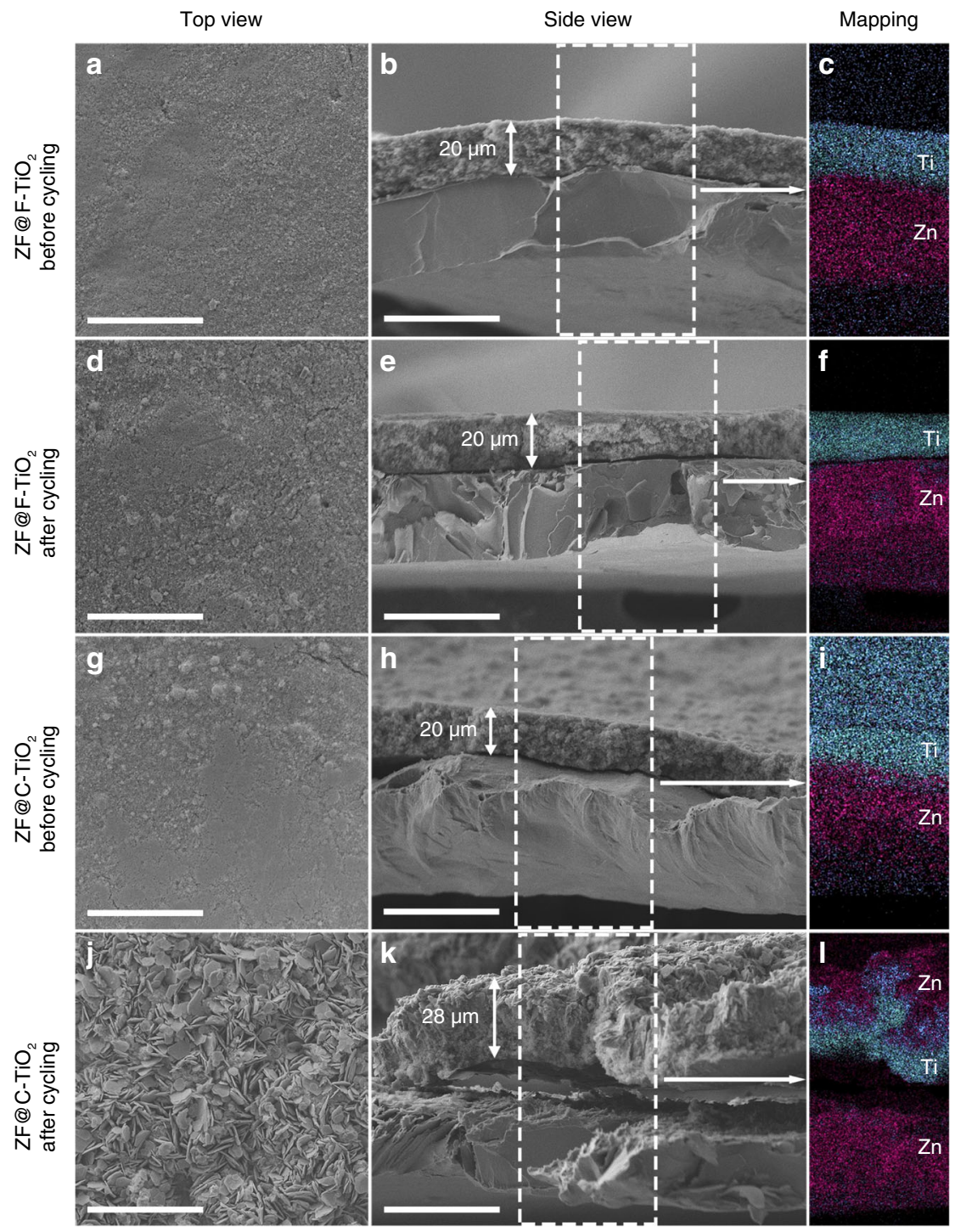

Fig. 3 Morphology evolution of the prepared $\mathbf{Z n}$ anodes. SEM and the corresponding EDX mapping images of a-f $Z \mathrm{~F} @ \mathrm{~F}-\mathrm{TiO} \mathrm{I}_{2}$ and $\mathbf{g}-\mathbf{I} \mathrm{ZF} @ \mathrm{C}-\mathrm{TiO} \mathrm{O}_{2}$ before and after 10 cycles in Zn-SS cells. Scale bar: $40 \mu \mathrm{m}$.

\section{Methods}

Synthesis of $\mathbf{F}-\mathrm{TiO}_{\mathbf{2}}$. Tetrabutyl titanate $(10 \mathrm{~mL}$, Aladdin) and hydrofluoric acid $(1.2 \mathrm{~mL}, 40 \mathrm{wt} \%$, Sinopharm) were added into a $50 \mathrm{~mL}$ Teflon-lined autoclave and then maintained at $180^{\circ} \mathrm{C}$ for $24 \mathrm{~h}$. The precipitates were collected by vacuum filtration then washed by ethanol and dried at $80^{\circ} \mathrm{C}$ for $6 \mathrm{~h}$

Fabrication of ZF@F-TiO 2 . F-TiO ${ }_{2}$ and PVDF were mixed in a weight ratio of 9:1 with NMP as the dispersant. The slurry was pasted onto $\mathrm{Zn}$ foil $(30 \mu \mathrm{m})$ and dried at $80^{\circ} \mathrm{C}$ for $24 \mathrm{~h}$ under vacuum. For comparison, $\mathrm{ZF} @ \mathrm{C}-\mathrm{TiO}_{2}$ was also prepared by replacing $\mathrm{F}-\mathrm{TiO}_{2}$ with $\mathrm{C}-\mathrm{TiO}_{2}$.

Characterizations. XRD was tested by a Bruker D8 X-ray diffractometer with monochromatized $\mathrm{Cu} \mathrm{K} \alpha$ radiation (wavelength $=1.5406 \AA$ ). Raman spectra were recorded using a Renishaw inVia spectrometer using an excitation wavelength of $532 \mathrm{~nm}$. Morphologies of the prepared $\mathrm{TiO}_{2}$ and $\mathrm{Zn}$ anodes were characterized by SEM (Nova NanoSEM 230) and TEM (Tecnai G2 F20 S-TWIN). The contact angle was measured by a drop shape analyzer (DSA100).

Electrochemical measurements. Coin-type cells (CR2025) were assembled for $\mathrm{Zn}-\mathrm{Zn}$ symmetric cells, $\mathrm{Zn}$-SS half cells and $\mathrm{Zn}-\mathrm{MnO}_{2}$ full cells with glass fiber as separator and $1 \mathrm{M}$ zinc sulfate $\left(\mathrm{ZnSO}_{4}\right)$ aqueous solution as the electrolyte. Battery performance was evaluated using a Neware battery testing system. CV measurement for $\mathrm{Zn}-\mathrm{Zn}$ symmetric cells was conducted on a CHI760E electrochemical workstation in the voltage range of $-0.1-0.1 \mathrm{~V}$. Zn-SS half cells were cycled with a specific capacity of $1 \mathrm{mAh} \mathrm{cm}^{-2}$ at $1 \mathrm{~mA} \mathrm{~cm}^{-2}$ for the charging process and a cutoff potential of $-0.3 \mathrm{~V}$ at $1 \mathrm{~mA} \mathrm{~cm}{ }^{-2}$ for the discharging process. Full cells were cycled between 1.0 and $2.0 \mathrm{~V}$ using commercial $\mathrm{MnO}_{2}$ (Macklin) as the cathode. In all, $0.1 \mathrm{M}$ manganese sulfate $\left(\mathrm{MnSO}_{4}\right)$ was added in the $\mathrm{ZnSO}_{4}$ electrolyte to prevent $\mathrm{Mn}^{2+}$ dissolution.

Computational details. The first-principles calculations were conducted using generalized gradient approximation (GGA) and Perdew-Burke-Ernzerhof (PBE) exchange-correlation functional in DMol3 module of Materials Studio (version 8.0) of Accelrys Inc. An all-electron numerical basis set with polarization functions (DNP basis set) and a DFT-D method within the Grimme scheme was employed. The convergence tolerance was set to $1.0 \times 10^{-5} \mathrm{Ha}$ $(1 \mathrm{Ha}=27.21 \mathrm{eV})$ for energy, $2.0 \times 10^{-3} \mathrm{Ha} \AA^{-1}$ for maximum force and $5.0 \times$ $10^{-3} \AA$ for maximum displacement. Common facets of $\mathrm{TiO}_{2}$ and $\mathrm{Zn}$ were investigated in this simulation, including $\mathrm{TiO}_{2}\left(\begin{array}{lll}0 & 0 & 1\end{array}\right), \mathrm{TiO}_{2}\left(\begin{array}{lll}1 & 0 & 0\end{array}\right), \mathrm{TiO}_{2}\left(\begin{array}{lll}1 & 0 & 1\end{array}\right)$ $\mathrm{Zn}\left(\begin{array}{lll}0 & 0 & 1\end{array}\right)$ and $\mathrm{Zn}\left(\begin{array}{lll}1 & 0 & 0\end{array}\right)$. Each facet was set as a five-layer $3 \times 3$ supercell with top three-layer atoms releasable. $\mathrm{Zn}$ atom was placed in the vertex of the oxygen octahedron of the $\mathrm{TiO}_{2}$ facet or the tetrahedral vertex of the $\mathrm{Zn}$ facet before geometry optimization. Binding energy $\left(E_{\mathrm{b}}\right)$ was calculated by the following equation:

$$
E_{\mathrm{b}}=E_{\text {total }}-E_{\text {sub }}-E_{\text {Zn }}
$$

$E_{\text {total }}, E_{\text {sub }}$, and $E_{\mathrm{Zn}}$ represent the total energy of the facet combined with $\mathrm{Zn}$ atom, the energy of the facet and the energy of $\mathrm{Zn}$ atom, respectively. 

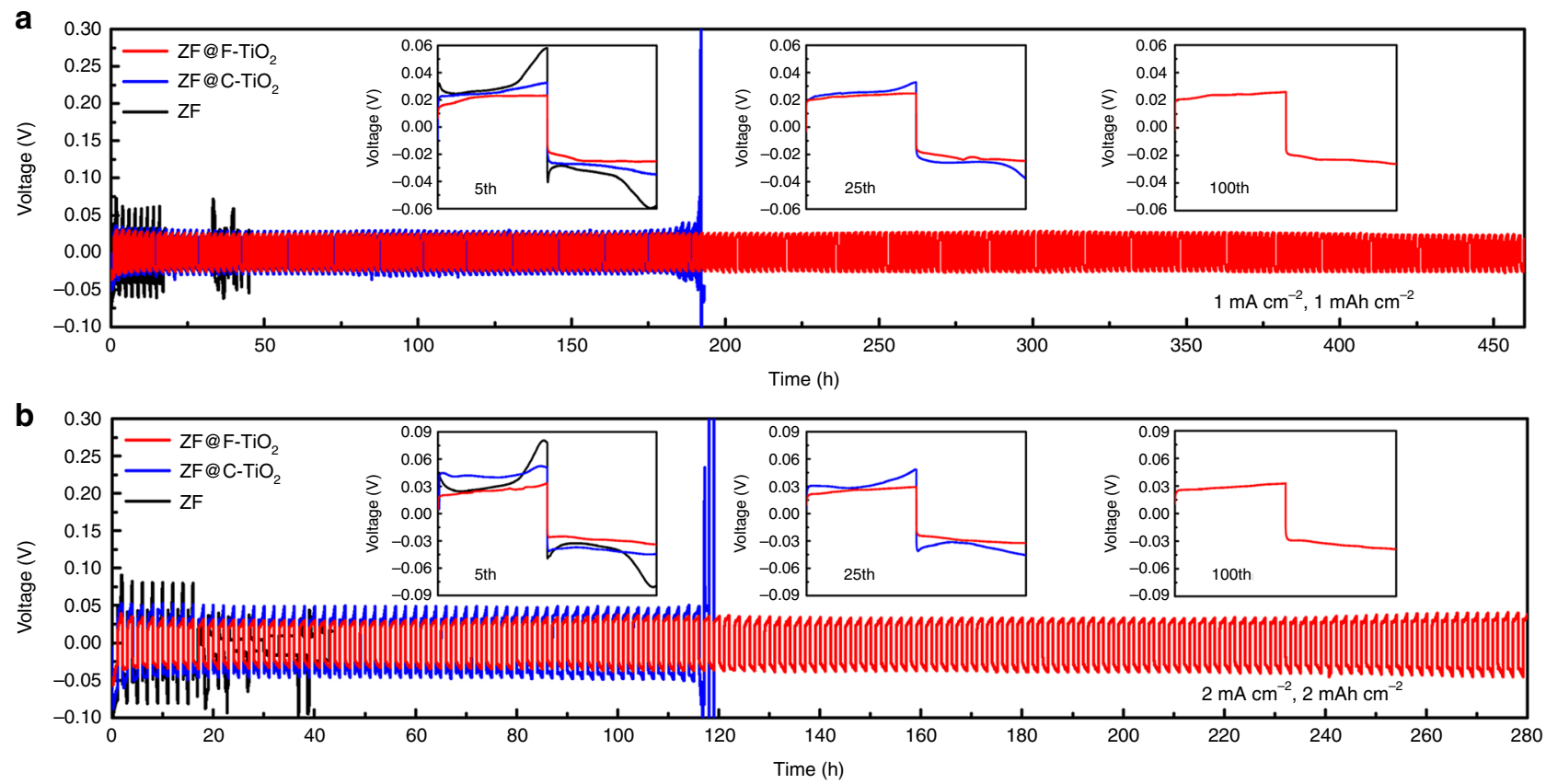

Fig. 4 Electrochemical performance of prepared Zn anodes. Cycling performance $Z n-Z n$ symmetric cells at a $1 \mathrm{~mA} \mathrm{~cm}^{-2}$ for $1 \mathrm{mAh} \mathrm{cm}^{-2}$ and $\mathbf{b} 2 \mathrm{~mA} \mathrm{~cm}^{-2}$ for $2 \mathrm{mAh} \mathrm{cm}^{-2}$.

\section{Data availability}

The data sets generated and/or analyzed in this study are available from the corresponding author on reasonable request.

Received: 24 November 2019; Accepted: 2 July 2020;

Published online: 07 August 2020

\section{References}

1. Lee, B., Paek, E., Mitlin, D. \& Lee, S. W. Sodium metal anodes: emerging solutions to dendrite growth. Chem. Rev. 119, 5416-5460 (2019).

2. Lu, Z. et al. Graphitic carbon nitride induced micro-electric field for dendritefree lithium metal anodes. Adv. Energy Mater. 9, 1803186 (2019).

3. Grey, C. P. \& Tarascon, J. M. Sustainability and in situ monitoring in battery development. Nat. Mater. 16, 45 (2016).

4. Shen, X. et al. Lithium anode stable in air for low-cost fabrication of a dendrite-free lithium battery. Nat. Commun. 10, 900 (2019).

5. Meng, J., Chu, F., Hu, J. \& Li, C. Liquid polydimethylsiloxane grafting to enable dendrite-free Li plating for highly reversible Li-metal batteries. Adv. Funct. Mater. 29, 1902220 (2019).

6. Wu, J. et al. Ultralight layer-by-layer self-assembled $\mathrm{MoS}_{2}$-polymer modified separator for simultaneously trapping polysulfides and suppressing lithium dendrites. Adv. Energy Mater. 8, 1802430 (2018).

7. Zhang, Q. et al. The Three-dimensional dendrite-free zinc anode on a copper mesh with a zinc-oriented polyacrylamide electrolyte additive. Angew. Chem. Int. Ed. 58, 2-9 (2019).

8. Yang, C. P., Yin, Y. X., Zhang, S. F., Li, N. W. \& Guo, Y. G. Accommodating lithium into 3D current collectors with a submicron skeleton towards long-life lithium metal anodes. Nat. Commun. 6, 8058 (2015).

9. Zeng, Y., et al. Dendrite-free zinc deposition induced by multifunctional CNT frameworks for stable flexible Zn-ion batteries. Adv. Mater. 31, 1903675 (2019).

10. Chen, X. et al. Lithiophilicity chemistry of heteroatom-doped carbon to guide uniform lithium nucleation in lithium metal anodes. Sci. Adv. 5, eaau7728 (2019).

11. Zhang, Q., Luan, J., Sun, D., Tang, Y. \& Wang, H. Plasma-treated $\mathrm{Ti}^{3+}$-doped sodium titanate nanosheet arrays on titanium foil as a lithiophilic current collector for a stable lithium metal anode. Chem. Commun. 55, 6551-6554 (2019).

12. Luan, J. et al. Plasma-strengthened lithiophilicity of copper oxide nanosheet-decorated $\mathrm{Cu}$ foil for stable lithium metal anode. Adv. Sci. 6 , 1901433 (2019).

13. Liu, F. et al. Fabrication of hybrid silicate coatings by a simple vapor deposition method for lithium metal anodes. Adv. Energy Mater. 8, 1701744 (2018).
14. Deng, K. et al. Single-ion conducting artificial solid electrolyte interphase layers for dendrite-free and highly stable lithium metal anodes. J. Mater. Chem. A 7, 13113-13119 (2019).

15. Xue, P., Sun, C., Li, H., Liang, J., \& Lai, C. Superlithiophilic amorphous $\mathrm{SiO}_{2}-\mathrm{TiO}_{2}$ distributed into porous carbon skeleton enabling uniform lithium deposition for stable lithium metal batteries. Adv. Sci. 6, 1900943 (2019).

16. Zhou, M., Lyu, Y., Liu, Y. \& Guo, B. Porous scaffold of $\mathrm{TiO}_{2}$ for dendrite-free lithium metal anode. J. Alloy. Compd. 791, 364-370 (2019).

17. Nan, Y., Li, S., Li, B. \& Yang, S. An artificial $\mathrm{TiO}_{2} /$ lithium n-butoxide hybrid SEI layer with facilitated lithium-ion transportation ability for stable lithium anodes. Nanoscale 11, 2194-2201 (2019).

18. Zhao, Z. et al. Long-life and deeply rechargeable aqueous $\mathrm{Zn}$ anodes enabled by a multifunctional brightener-inspired interphase. Energy Environ. Sci. 12, 1938-1949 (2019)

19. Bai, M. et al. A scalable approach to dendrite-free lithium anodes via spontaneous reduction of spray-coated graphene oxide layers. Adv. Mater. 30, 1801213 (2018)

20. Li, C. et al. Facet-dependent photoelectrochemical performance of $\mathrm{TiO}_{2}$ nanostructures: an experimental and computational study. J. Am. Chem. Soc. 137, 1520-1529 (2015)

21. Wang, S., Liu, G. \& Wang, L. Crystal facet engineering of photoelectrodes for photoelectrochemical water splitting. Chem. Rev. 119, 5192-5247 (2019).

22. Liu, G. et al. Enhanced photoactivity of oxygen-deficient anatase $\mathrm{TiO}_{2}$ sheets with dominant $\{001\}$ facets. J. Phys. Chem. C. 113, 21784-21788 (2009).

23. D'Agostino, A. Determination of thin metal film thickness by X-ray diffractometry using the Scherrer equation, atomic absorption analysis and transmission/reflection visible spectroscopy. Anal. Chim. Acta 262, 269-275 (1992).

24. $\mathrm{Zhu}$, J. et al. Solvothermally controllable synthesis of anatase $\mathrm{TiO}_{2}$ nanocrystals with dominant $\{001\}$ facets and enhanced photocatalytic activity. Cryst. Eng. Commun. 12, 2219-2224 (2010).

25. Wang, J., Zhang, P., Li, X., Zhu, J. \& Li, H. Synchronical pollutant degradation and $\mathrm{H}_{2}$ production on $\mathrm{a} \mathrm{Ti}^{3+}$-doped $\mathrm{TiO}_{2}$ visible photocatalyst with dominant (001) facets. Appl. Catal. B: Environ. 134, 198-204 (2013).

26. Liu, X., Dong, G., Li, S., Lu, G. \& Bi, Y. Direct observation of charge separation on anatase $\mathrm{TiO}_{2}$ crystals with selectively etched $\{001\}$ facets. J. Am. Chem. Soc. 138, 2917-2920 (2016).

27. Xu, H., Ouyang, S., Li, P., Kako, T. \& Ye, J. High-active anatase $\mathrm{TiO}_{2}$ nanosheets exposed with $95 \%\{100\}$ facets toward efficient $\mathrm{H}_{2}$ evolution and $\mathrm{CO}_{2}$ photoreduction. ACS Appl. Mater. Interfaces 5, 1348-1354 (2013).

28. Tian, F., Zhang, Y., Zhang, J. \& Pan, C. Raman Spectroscopy: A new approach to measure the percentage of anatase $\mathrm{TiO}_{2}$ exposed (001) facets. J. Phys. Chem. C. 116, 7515-7519 (2012).

29. Jun, Y. et al. surfactant-assisted elimination of a high energy facet as a means of controlling the shapes of $\mathrm{TiO}_{2}$ nanocrystals. J. Am. Chem. Soc. 125, 15981-15985 (2003). 
30. $\mathrm{Wu}, \mathrm{N}$. et al. Shape-enhanced photocatalytic activity of single-crystalline anatase $\mathrm{TiO}_{2}$ (101) nanobelts. J. Am. Chem. Soc. 132, 6679-6685 (2010).

31. Yang, Q. et al. Do zinc dendrites exist in neutral zinc batteries: a developed electrohealing strategy to in situ rescue in-service batteries. Adv. Mater. 31, 1903778 (2019).

32. Zhang, Q. et al. A facile annealing strategy for achieving in situ controllable $\mathrm{Cu}_{2} \mathrm{O}$ nanoparticle decorated copper foil as a current collector for stable lithium metal anodes. J. Mater. Chem. A 6, 18444-18448 (2018).

33. Zhang, C. et al. A $\mathrm{ZnCl}_{2}$ water-in-salt electrolyte for a reversible $\mathrm{Zn}$ metal anode. Chem. Commun. 54, 14097-14099 (2018).

34. Xie, X. et al. Manipulating the ion-transfer kinetics and interface stability for high-performance zinc metal anodes. Energy Environ. Sci. 13, 503-510 (2020).

35. Zuo, T. et al. Graphitized carbon fibers as multifunctional 3D curren collectors for high areal capacity Li anodes. Adv. Mater. 29, 1700389 (2017).

\section{Acknowledgements}

This research was financially supported by the National Nature Science Foundation of China (No. 21975289), Hunan Provincial Research and Development Plan in Key Areas (2019GK2033) and Hunan Provincial Science and Technology Plan Project of China (No. 2017TP1001 and No. 2018RS3009).

\section{Author contributions}

H.W. designed the experiment and participated in the analysis of results and in discussing and writing the paper. Q.Z. participated in the experimental design, synthesized the samples, carried out the characterizations and wrote the manuscript. Y.T. provided valuable advice and participated in helpful discussions. X.H and D.S. analyzed the data and edited the paper. X.J participated in discussions on the paper. J.L and Q.W. helped to characterize the materials. All authors have read and approved the final paper.

\section{Competing interests}

The authors declare no competing interests.

\section{Additional information}

Supplementary information is available for this paper at https://doi.org/10.1038/s41467 020-17752-x.

Correspondence and requests for materials should be addressed to H.W.

Peer review information Nature Communications thanks Seung-Tae Hong, and the other, anonymous, reviewer(s) for their contribution to the peer review of this work.

Reprints and permission information is available at http://www.nature.com/reprints

Publisher's note Springer Nature remains neutral with regard to jurisdictional claims in published maps and institutional affiliations.

(c) Open Access This article is licensed under a Creative Commons Attribution 4.0 International License, which permits use, sharing, adaptation, distribution and reproduction in any medium or format, as long as you give appropriate credit to the original author(s) and the source, provide a link to the Creative Commons license, and indicate if changes were made. The images or other third party material in this article are included in the article's Creative Commons license, unless indicated otherwise in a credit line to the material. If material is not included in the article's Creative Commons license and your intended use is not permitted by statutory regulation or exceeds the permitted use, you will need to obtain permission directly from the copyright holder. To view a copy of this license, visit http://creativecommons.org/licenses/by/4.0/.

(C) The Author(s) 2020 